\title{
Anterior Tongue Adenoid Cystic Carcinoma
}

National Cancer Institute

\section{Source}

National Cancer Institute. Anterior Tongue Adenoid Cystic Carcinoma. NCI Thesaurus.

Code C6251.

An adenoid cystic carcinoma arising from the minor salivary glands in the anterior tongue. 